\title{
OS PROCESSOS DE ARTICULAÇÃO DE ORAÇÕES SOB DIFERENTES ABORDAGENS: UM OLHAR PARA : A HIPOTAXE ADVERBIAL
}

\section{THE PROCESSES OF ARTICULATION OF SENTENCES THROUGH DIFFERENT APPROACHES: A GLANCE AT ADVERBIAL HYPOTAXIS}

Marta Anaísa Bezerra Ramos (UEPB) ${ }^{1}$ Camilo Rosa Silva (UFPB) ${ }^{2}$

\section{RESUMO}

Neste artigo, caracterizamos os processos de articulação oracional, em particular, o mecanismo referido por "hipotaxe adverbial", enfatizando seu importante papel na organização da coerência textual. Nessa perspectiva, apresentamos uma visão panorâmica das diferentes abordagens sobre o tema, procurando mostrar que, enquanto a abordagem tradicional se centra na análise da sentença, os estudos funcionalistas ampliam esse enfoque, explorando outros níveis de análise além do sintático. Para explicação dos processos de articulação, trazemos, como ilustração, fragmentos de textos de teor argumentativo, e, a partir da observação de outros aspectos relacionados à organização textual, como a pontuação, ordem de ocorrência e relevância das informações, e também o vocabulário, enfatizamos a relação entre organização sintática e construção da textualidade. A partir daí, propomos uma atividade que conduz à reflexão em torno das escolhas dos usuários da língua. Neste estudo, além da referência a gramáticos como Bechara(1999) e Perini (1996), reportamo-nos a autores funcionalistas, tais como Halliday (1985), Matthiessen e Thompson (1988), Lehmann (1988) e Hopper e Traugott (1993), dentre outros.

PALAVRAS-CHAVE: articulação oracional; hipotaxe adverbial; gramaticalização; textualidade.

1 Doutora em Linguística pela Universidade Federal da Paraíba. Email: martaanaisa@gmail. com

2 Doutor em Letras pela Universidade Federal da Paraíba. Email: camilorosa@gmail.com 


\begin{abstract}
In this article, we characterize the processes of the articulation of sentences, in particular, the mechanism known as "adverbial hypotaxis", emphasizing its important role in the organization of textual coherence. In this perspective, we present a panoramic vision of different approaches to this theme, attempting to show that while the traditional approach centers on the analysis of the sentence, functionalist studies amplify this focus, exploring other levels of analysis besides the syntactic level. To explain and illustrate the processes of articulation, we bring fragments of texts in the argumentative mode. From the observation of other aspects related to textual organization, such as punctuation, the order of occurrence and relevance of information, as well as the vocabulary, we emphasize the relationship between syntactic organization and the construction of textuality. Taking this as the starting point, we propose an activity leading to reflection about the linguistic choices of language users. In this study, besides reference to grammarians such as Bechara (1999) and Perini (1996), we have also referred to functionalist authors such as Halliday (1985), Matthiessenand Thompson (1988), Lehmann (1988) and Hopper and Traugott (1993), among others.
\end{abstract}

KEYWORDS:articulation of sentences; adverbial hypotaxis; grammaticalization; textuality.

\title{
INTRODUÇÃO
}

Não obstante as inovações incorporadas ao processo de ensinoaprendizagem da Língua Portuguesa, resultantes das pesquisas advindas de diversas perspectivas teóricas, implicando melhorias nos materiais didáticos produzidos a partir dos anos 90 e também nas ações dos professores em sala de aula, quando se trata, sobretudo, da exploração de tópicos gramaticais, fatores vários - que passam pela falta de tempo para preparar aulas até a insegurança quanto ao referencial teórico obstaculam uma abordagem satisfatória desses tópicos. Os documentos institucionais, por sua vez, a exemplo dos PCN, propõem como uma 
das diretrizes para o ensino a ativação da capacidade epilinguística dos alunos, o que se faz através da reflexão sobre as escolhas linguísticas e sua adequação às diversificadas situações de uso. Mas o ensino de conteúdos gramaticais ainda prioriza a apreensão da metalinguagem em detrimento da análise dos recursos linguísticos empregados na construção dos sentidos articulados nos textos.

É oportuno destacarmos que, muitas vezes, apontam-se críticas ao trabalho com o texto, com base no argumento de que, apesar de ter mudado o suporte de análise, a abordagem continua centrada no reconhecimento e classificação de funções gramaticais, de modo que o texto serve apenas como pretexto para a exploração de taxonomias. Mas, como afirma Neves (2012, p.204), o texto deve ser um meio para verificar "nos (variados) usos tudo o que é possível fazer com a linguagem e obter com a linguagem: exatidão (quando essa for a intenção); elevação ou banalização (quando essa for a relevância); redundância ou inacabamentos (quando essa for a necessidade) etc." Nesse sentido, estudar os processos de articulação oracional no texto significa explorar a relação entre a organização sintática e a construção da textualidade, ultrapassando a mera classificação das orações em coordenadas ou subordinadas, cujo critério de identificação, muitas vezes, norteia-se apenas pelo tipo de conjunção que as introduz.

Apoiados numa perspectiva de estudo da gramática sob o viés funcionalista, que considera na análise da língua o contexto efetivo de uso, observando a interação entre o formal, o funcional, o pragmático e o discursivo, interessa-nos, neste artigo, descrever, inicialmente, as propostas de estudode Bechara (1999) e de Perini (1996) acerca dos processos de articulação oracional, por considerarmos que as abordagens de ambos os autores se aproximam e representam um avanço às abordagens tradicionais. Na sequência, apresentamos, em linhas gerais, referências aos trabalhos de estudiosos comoHalliday (1985), Matthiessen e Thompson (1988), Lehmann (1988) e Hopper e Traugott (1993) sobre os mecanismos de articulação de orações, tendo em vista esses autores contemplarem, em suas análises, outros níveis, além do sintático. Por fim, particularmente em relação às orações adverbiais, sugerimos uma atividade que explora outros aspectos também relacionados à configuração das orações, como escolhas lexicais, pontuação, ordem de ocorrência e relevância das informações, 
: pressupondo que a língua disponibiliza diferentes recursos para promover a articulação de orações e parágrafos, cabendo ao usuário ativar um modo de dizer que melhor expresse sua intenção comunicativa.

Ao lado das reflexões que tentamos estabelecer acerca da articulação de orações, nossa perspectiva não é de defender, no ensino de português, a exploração exclusiva da epilinguagem, mas promover uma discussão acerca do espaço que esta deve compartilhar com a metalinguagem.

\section{Um panorama dos processos de articulação dos períodos: visitando a tradição}

O modo como as sentenças se interligam no período e este se interrelaciona com outros períodos, parágrafos e partes do texto, na composição textual é campo de estudo da coesão interfrásica. Nesse contexto, conforme "o tipo de unidades linguísticas conectadas e o tipo de unidade resultante de tal conexão” (DUARTE, in MIRA MATEUS, 2003, p. 91), dois mecanismos distintos promovem a conexão - a parataxe (relação entre elementos de mesmo estatuto) e a hipotaxe (relação entre elementos de estatuto diferente). Grosso modo, faz-se a associação entre o primeiro mecanismo e a coordenação e entre o segundo e a subordinação. Mas, conforme Duarte (op. cit.), a parataxe acomoda as orações parentéticas, as interrogativas tag e os pares pergunta/resposta, estruturas que têm em comum o aspecto da independência sintática, embora em diferentes graus, mas que não admitem serem parafraseadas pela coordenação sindética com os conectores “e”, "mas” e "ou”. Logo, a coordenação é um dos tipos de relação paratática. $\mathrm{Na}$ abordagem realizada por essa autora, hipotaxe é sinônimo de subordinação; no entanto, subordinação é um termo que melhor se aplica às orações complexas de natureza completiva, no caso, as substantivas. Na sequência, tecemos considerações mais pontuais sobre os processos de combinação oracional.

Tradicionalmente se distinguem dois mecanismos de construção do período: acoordenação, que consiste na combinação de orações de mesma natureza e função, já que uma oração não é termo da outra, ou seja, nenhuma delas representa função em outra; e a subordinação, que implica relação de natureza hierárquica, já que uma oração, obedecendo à estrutura de constituintes, é termo de outra. Significa dizer que, nesse segundo 
processo, há sobreposição de camadas; de modo que o termo oracional (complemento) que está em relação argumental com o predicador (verbo) : é caracterizado como subordinado, dando origem à oração subordinada. Conforme a função do constituinte, as subordinadas se subclassificam em substantiva, adjetiva ou adverbial- as funções de sujeito, objeto direto, objeto indireto, complemento relativo, predicativo, aposto são contempladas no primeiro grupo; e as funções de adjunto adnominal e adjunto adverbial, no segundo e terceiro grupos, respectivamente. Quanto à oração que as contém é denominada principal.

Abordagens como as de Perini (1996) e de Bechara (1999), que destacam o princípio da recursividade, adotam a denominação oração complexa em substituição aperíodo composto. Para Bechara (op. cit., p. 463), esse segundo termo só se aplicaria às coordenadas; embora ele prefira se referir a estas por grupos oracionais, que implicam um processo em que elementos de uma "mesma camada gramatical”, no caso, orações, se integram para formar um todo, embora cada oração possa ocorrer em separado. Já a subordinação implica transposição de camadas, considerando que uma unidade superior - oração - pode, nos termos do autor (op. cit., p. 462), "pelo fenômeno de estruturação de camadas gramaticais conhecido por hipotaxe on subordinação passar a uma camada inferior e aí funcionar como pertença, como membro sintático de outra unidade”. Para explicar esse raciocínio, consideremos os exemplos (1) e (2) abaixo, extraído de Veja $(01 / 04 / 15)$ :

1) A Olimpíada vai projetar a imagem de um Brasil eficiente, sério e honesto.

2) O prefeito do Rio de Janeiro aposta que a Olimpíada vai projetar a imagem de um Brasil eficiente, sério e honesto.

Movidos por essa maneira de analisar o fenômeno, devemos entender que a oração (1) perdeu o status de oração absoluta e passou a ser membro de outra, logo subordinada.

Perini (1996, p.124), por sua vez, define a oração complexa como aquela que "contém dentro de seus limites pelo menos uma outra oração". Subordinada é a que faz parte de um termo de outra. No caso da coordenação, o conjunto de duas ou mais orações, da mesma categoria, 
forma uma outra; ou seja, a oração na íntegra contém as demais a ela subordinadas. Assim, retomando o exemplo (2)

(2’) [O prefeito do Rio de Janeiro aposta (que a Olimpíada vai projetar a imagem de um Brasil eficiente, sério e honesto.) $\left.\mathrm{O}^{2}\right] \mathrm{O}^{1}$

Observamos que a $\mathrm{O}^{1}$, que é a oração completa, contém a $\mathrm{O}^{2}(\mathrm{a}$ Olimpíada vai projetar a imagem de um Brasil eficiente, sério e honesto) que é parte de um termo da principal; logo, a $\mathrm{O}^{2}$ está subordinada a $\mathrm{O}^{1}$. Como esse termo/constituinte, no caso o OD, complementa o verbo da principal, diz-se que está encaixado, daí a oração ser classificada como substantiva/completiva objetiva direta. A vantagem dessa proposta, se raciocinarmos conforme o autor, está em atender ao princípio de que um termo de uma oração é parte dela. Logo, para ele, a primeira parte da informação constitui apenas um pedaço de oração. Considerando a oração na íntegra como principal, mantém-se, pois, a ideia de que uma oração subordinada é parte da principal. Segue a análise de um período que conjuga os dois processos - coordenação e subordinação:

(3) $\left[\left\{\mathrm{O}\right.\right.$ prefeito do Rio de Janeiro critica o governo federal $\left.\mathrm{O}^{1}\right\}\{\varnothing$ defende a alternância de poder $\left.\mathrm{O}^{2}\right\}$ e $\{\varnothing$ aposta (que a Olimpíada vai projetar a imagem de um Brasil eficiente, sério e honesto). $\left.\mathrm{O}^{3}\right\}$ ] $=\mathrm{O}^{4}($ Veja, 01/04/15)

Nesse exemplo, cada oração corresponde a um membro da oração maior, que é a oração na íntegra, podendo ser assim representado $\mathrm{O}^{1}=$ $\left[\left\{\mathrm{O}^{2}\right\}+\left\{\mathrm{O}^{3}\right\}+\left\{\mathrm{O}^{4}\right\}\right]$. Portanto, as orações 2,3 e 4 são membros de coordenação de 1 . Ou melhor, os três membros de coordenação (MC) estão subordinados a oração maior, tomada como principal. Convém esclarecer que o terceiro membro de coordenação contém outra oração a ela subordinada. Logo, retomando o exemplo, de modo a contemplar esse ponto, considere-se a segmentação:

(3’) $\left[\left\{\mathrm{O}\right.\right.$ prefeito do Rio de Janeiro critica o governo federal $\left.\mathrm{O}^{2}\right\}$ $\left\{\varnothing\right.$ defende a alternância de poder $\left.\mathrm{O}^{3}\right\}$ e $\{\varnothing$ aposta (que a Olimpíada vai projetar a imagem de um Brasil eficiente, sério e honesto.) $\left.\left.\mathrm{O}^{5}\right\} \mathrm{O}^{4}\right] \mathrm{O}^{1}$

3 Como o modelo de segmentação de orações proposto por Perini difere do modelo da tradição, especificamos a legenda: [...] or. principal; (...) or. subordinada; $\{. .$. or. coordenada. 
Conforme o critério de contagem das orações proposto por Perini, no exemplo (3’) supracitado há 5 orações, pois a $\mathrm{O}^{1}$, que é a oração : completa, contém três membros de coordenação: $\mathrm{O}^{2}, \mathrm{O}^{3}$ e $\mathrm{O}^{4}$. Esta última, por sua vez, contém uma outra, a $\mathrm{O}^{5}$ a ela subordinada.

Se, de um lado, o tratamento do período composto na gramática tradicional limita-se ao plano da superfície da sentença,estudiososdas várias correntes do funcionalismo ${ }^{4}$, a exemplo de Halliday (1985), Matthiessen e Thompson (1988), Lehmann (1988) e Hopper e Traugott (1993), discordando da crença de que só existem duas estratégias de articulação oracional - a coordenação e a subordinação, em cuja base está a noção de dependência/independência sintático-semântica -, redirecionam o tratamento das orações complexas, distribuindo as estruturas oracionais em três grupos: parataxe, hipotaxe e subordinação. Esse é o tema da seção subsequente.

\section{Processos de combinação de orações: novas perspectivas de abordagem}

Halliday (1985), discordando da distinção estabelecida pela tradição, que entende coordenação e subordinação como processos estanques, propõe outro modelo, alicerçado no estabelecimento de dois eixos que, integrados, terminam por reorganizar o quadro das orações complexas. Em consequência, delineiam-se três categorias: a relação paratática, a relação hipotática e a relação deconstituência. Conforme mencionado, dois eixos norteiam essa visão - o sistema tático e o sistema lógico-semântico: o primeiro leva em conta a correlação entre elementos, daí denominar de parataxe a relação entre elementos de mesmo estatuto e de hipotaxe, a relação entre elementos de estatuto diferente; o segundo eixo considera o papel semânticofuncional, daí a divisão entre a relação de expansão e a de projeção.

Restringindo-nos, por ora, ao que se chama expansão, lembramos que esta abriga relações lógico-semânticas como: elaboração, em que "uma oração elabora o significado de outra, especificando-a; o modelo de conjunção é isto ê"; extensão, "em que uma oração amplia o significado da outra, acrescentando algo novo a ela; a conjunção típica desse processo é e”; e realce, em que "uma oração realça o significado da outra, qualificando-a

4 Ressaltamos que não há apenas um modelo funcionalista, há visões diferenciadas conforme o prisma de observação, embora apresentem pontos convergentes. 
: quanto a tempo, lugar, modo, causa ou condição; as conjunções típicas : são assim e então". É importante destacarmos que as orações adjetivas não se enquadram nem na relação de parataxe nem na de hipotaxe, porque são estruturas encaixadas, que não mantêm uma "relação", mas fazem parte da estrutura de um sintagma, sintagma este constituinte da frase.

Proposta de grande relevância para a compreensão do processo de articulação é elaboradapor Matthiessen e Thompson (1988), que ampliam o modelo de Halliday, ancoradas na visão de que ao critério sintático, deve-se somar o das funções discursivas. Além disso, referindose às orações adverbiais, argumentam as autoras que a combinação de orações"reflete a organização retórica do discurso: relações como causa, condição, concessão, etc. são relações que existem entre quaisquer partes de um texto, e que podem gramaticalizar-se na combinação de orações [...].” (NEVES, 2006, p.229)

Essas relações retóricas compreendem as relações de listagem (parataxe) e relações núcleo-satélite (hipotaxe). Neste segundo modelo estrutural, uma das orações apresenta a informação que realiza o objetivo central do autor e a outra serve de suporte para esses objetivos ou um objetivo suplementar. Parafraseando Neves (2006, p.230), a decisão quanto ao grau de importância da informação - se é nuclear ou subsidiária será determinada na interação, pois, no processo de elaboração textual, já há uma expectativa do falante/escritor de que o interlocutor/leitor faça um julgamento sobre a "nuclearidade ou a suplementaridade das partes, julgamento que é regido cognitivamente".

Lehmann (1988) como também Hopper e Traugott (1993) são defensores de que no processo de combinação de orações, as cláusulas que formam a oração complexa refletem diferentes graus de integração. Nessa perspectiva, Lehmann (op. cit., p. 217) analisa as orações a partir de três critérios gerais, a saber: (i) autonomia ou integração de cláusulas subordinadas; (ii) expansão ou redução da cláusula subordinada ou principal; e (iii) isolamento ou articulação de cláusulas. Cada um desses aspectos se desmembra em pares, resultando nos seis parâmetros de avaliação: rebaixamento hierárquico da cláusula subordinada;nível sintático do constituinte ao qual a oração subordinada se vincula; dessentencialização da subordinada; gramaticalização do verbo principal; entrelaçamento das duas orações; explicitude da articulação. 
De acordo com o autor, as tipologias oracionais atendem a um continuum de organização, obedecendo a um trajeto conforme o qual, no pólo à esquerda, situam-se as orações cujo vínculo é mais fraco, a exemplo das sentenças de igual estatuto sintático (paratáticas); no pólo à direita, ficam as orações cujo vínculo é mais forte, ou seja, as sentenças que se integram a outro constituinte da oração principal (é o caso das sentenças encaixadas ou subordinadas), e no pólo intermediário, estão cláusulas adverbiais, cláusulas nominais dessentencializadas, cláusulas correlatas, etc. Os critérios indicados por Lehmann (1988) são resgatados, sobretudo, em estudos que tratam da gramaticalização de orações ${ }^{5}$ que representam atitudes dos falantes, as chamadas orações modalizadoras, advindas de orações complexas formadas com orações completivas. Mas também se aplicam a orações adverbiais que tendem à nominalização.

Hopper e Traugott (1993), considerando parâmetros sintáticos e semântico-discursivos e adotando a ideia de continuum, também sugerem que o processo de junção das orações segue a direção de menor para maior integração de cláusulas, e em decorrências desse fator, o elo oracional é mínima ou maximamente explicitado, como revela o esquema proposto pelos autores:

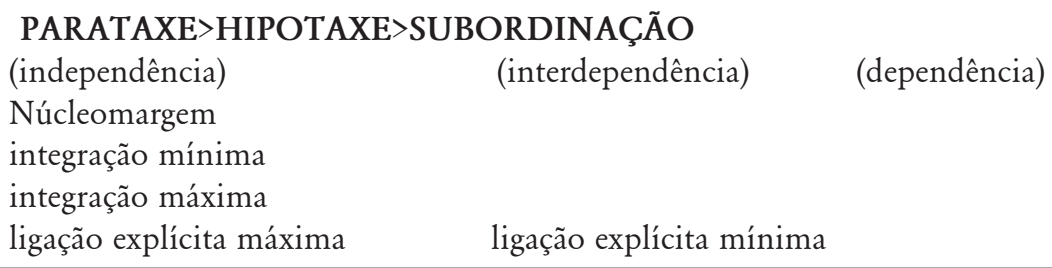

Quadro (1): Caracterização das tipologias oracionais que adotam a visão de contínuo

5 Ilustram casos de modalização estruturas como "acho" e "parece", em que ocorre redução ou dessentencialização de orações; e estruturas cristalizadas como "vai ver que", que revela o uso gramaticalizado do verbo da oração principal, correspondendo ao advérbio provavelmente. Quanto às adverbiais, servem de ilustração as orações finais. Azevedo (2000) apresenta, em sua tese, uma tipologia de estruturas que expressam finalidade, contemplando orações desenvolvidas e reduzidas, além de estruturas fortemente nominalizadas, como "Os países que, historicamente, mais contribuíram para a contaminao ambiental têm uma responsabilidade maior a respeito.” 
E, a depender dos traços dependência e encaixamento, obtém-se a seguinte configuração das diferentes tipologias oracionais:

\begin{tabular}{|c|c|c|}
\hline PARATAXE & HIPOTAXE & $\begin{array}{c}\text { SUBORDIN./ } \\
\text { ENCAIXAMENTO }\end{array}$ \\
\hline $\begin{array}{c}\text { coordenadas e justa- } \\
\text { postas }\end{array}$ & $\begin{array}{c}\text { adverbiais e } \\
\text { adjetivas expli- } \\
\text { cativas (aposi- } \\
\text { tivas) }\end{array}$ & $\begin{array}{c}\text { subordinadas substantivas } \\
\text { eadjetivas (restritivas) }\end{array}$ \\
\hline $\begin{array}{l}\text { (- dependência /- en- } \\
\text { caixamento) }\end{array}$ & $\begin{array}{l}\text { (+ dependência } \\
\text { /- encaixamen- } \\
\text { to })\end{array}$ & $\begin{array}{c}\text { (+ dependência /+ encaixa- } \\
\text { mento) }\end{array}$ \\
\hline
\end{tabular}

Quadro(2):Correspondência das tipologias oracionais: visão funcional e visão tradição

A contribuição dessas últimas abordagens consisteem permitir que se reconheçam com mais segurança as propriedades das diversas tipologias oracionais, por conciliar os critérios dependência e encaixamento. Além disso, a consideração do eixo lógico-semântico sinalizado por Halliday (1985), como argumenta Braga (2001, p. 25), "fornece respaldo à intuição de que uma mesma relação semântica pode ser codificada por diferentes estratégias sintáticas". Com isso, evita-se que o estudo dos processos de combinação oracional se restrinja à mera associação entre tipologia de oração e/ou tipologia de relação semântica, em conformidade com o conector que faz o elo oracional.

\section{A hipotaxe adverbial: caracterização sintática e semântico- funcional}

Reportando-nos a Brito (2003), apresentamos, neste espaço, uma síntese dos traços sintáticos caracterizadores desse tipo de oração. Conforme a autora, três propriedades sintáticas identificam uma oração subordinada adverbial: i) o papel de constituinte sintático; ii) o caráter nãoargumental em relação ao verbo da oração matriz; e iii) a impossibilidade de extração de constituintes na oração subordinada, daí a denominação de ilhas adjuntas. 
A submissão ao processo de clivagem e a mobilidade de posição (inicial/final/medial) confirmam o rótulo de um termo sintático. Quanto à propriedade de não ser argumento do predicado, a autora enumera quatro estratégiasindicadoras de adjunção, quais sejam:

i) a pergunta com o verbo fažer/acontecer seguido da oração subordinada cuja resposta é a oração matriz. Assim, dada a oração "Vamos jantar se vieres cedo.", obtém-se como resposta à pergunta "O que é que vamos fazer se vieres cedo?", a seguinte oração: "Vamos jantar".

ii) a substituição da oração adverbial por advérbios, sintagmas adverbiais e preposicionais, não argumentais. Nesse caso, a oração subordinada presente em "Vamos jantar quando chegares" pode ser substituída por "Vamos jantar às oito horas/hoje." Da mesma forma que à oração subordinada grifada em "Vou sair apesar de ter muito trabalho." pode corresponder a expressão "apesar do trabalho".

iii) evidência de correferencialidade entre o sujeito nulo da oração subordinada anteposta e o SN sujeito da oração matriz. Logo, no período "Embora ainda não $\varnothing$ tenha emprego, o João quer casar.", o sujeito nulo do verbo TER presente na oração subordinada é correferencial ao sujeito (João) da locução verbal QUER CASAR na oração matriz.

Ausência de correferencialidade entre o sujeito da oração subordinada adverbial quando posta à direita (posposta) e o sujeito nulo ou pronominal da oração matriz, como demonstra o exemplo "ela dançava, quando a Maria cantava, no qual o sujeito representado pelo pronome ela se refere a outra pessoa que não Maria.

Os traços estruturais acima relacionados conduzem a compreensão de que as orações adverbiais são parte de outra; mas, conforme alerta Decat (2001, p. 106), apesar de tais orações aparentarem ser encaixadas, têm "mais que uma função gramatical, uma função discursiva, no sentido de orientar o ouvinte para a mensagem que se quer transmitir, organizando, assim, a forma do discurso".

Por essa razão é que, numa perspectiva funcionalista, o estudo das orações adverbiais ultrapassa a identificação, no nível das sentenças, do tipo de informação que é adicionada à oração matriz por meio da 
associação à tipologia de advérbios, pois, além de nem sempre ocorrer : tal correspondência, pode também a oração adverbial ter como alvo/ escopo um grupo de sentenças. Portanto, está-se no nível textual e não no sentencial. O reconhecimento dessa particularidade das orações adverbiais faz com que funcionalistas como Castilho, Decat, Antonio, entre outros, prefiram descrevê-las como um princípio de organização do discurso, ou “como um caso de 'combinação de cláusulas”" (CASTILHO, 2010, p. 371).

Haiman e Thompson (1984, apud Decat, 2001, p. 110), seguindo essa lógica, distinguem cláusulas que se integram estruturalmente em outra (substantivas e adjetivas restritivas) de cláusulas que não se integram estruturalmente em outra (adverbiais). Voltando-se para o estudo destas últimas, os autores as subclassificam, conforme a combinação que estabelecem com as outras orações, em dois tipos, a saber: a) relação núcleo/satélite e b) relação de listagem. A diferença entre esses dois grupos está vinculadaà quantidade de texto com que a oração adverbial se estrutura. Assim, no primeiro caso, a articulação se dá entre duas sentenças - a matriz (núcleo) e a adverbial (satélite); no segundo, mais de uma oração adverbial; logo, vários satélites, estando numa relação paradigmática (listagem), mantêm uma relação hipotática com a matriz.

Uma vez que a articulação oracional é viabilizada não só por conjunções mas também por certas preposições, Neves (2000), ao situar o contexto de uso em que se aplicam essas formas gramaticais, estabelece uma oposição entre dois processos combinatórios - a subordinação estrita e a junção. A primeira atua no âmbito dos sintagmas ou das orações por meio das preposições, enquanto a segunda, no âmbito das relações entre satélites adverbiais e seus núcleos, podendo ser viabilizada tanto por meio das preposições quanto das conjunções subordinativas, denominação esta que, para a autora, é inadequada, pois só se aplicaria aos casos em que a ligação se dá entre uma oração substantiva ou adjetiva e a principal. Azeredo (2000, p. 211) utiliza o termo conjunções adverbiais para se referir aos casos em que tais conjunções "juntam-se a orações para formar sintagmas adverbiais" cujo resultado é a oração subordinada adverbial.

Feita essa síntese do tratamento que tem sido destinado ao estudo das relações que se estabelecem entre orações, proporemos, na próxima seção, uma análise das adverbiais ambientadas no escopo textual ediscursivo. 


\subsection{Analisando o funcionamento das orações adverbiais no texto}

A função de adjunção, em contrapartida à de constituinte, é a : propriedade que distingue as subordinadas adverbiais das substantivas, ou encaixadas. Em decorrência desse papel de predicação das primeiras, na medida em que adicionam informações de acordo com as necessidades do discurso, tais orações revestem-se de grande importância. De acordo com Antonio (2008), a forma de combinação das orações é a representação material da organização do discurso, comprovando que os diferentes gêneros de texto apresentam sequências linguísticas específicas de acordo com o tipo de relação retórica evidenciada nas porções textuais, confirmando o princípio defendido pelo "funcionalismo da Costa-Oeste" de que há uma relação entre a gramática e o discurso.

Convém destacar que o tratamento da articulação oracional nas gramáticas, costumeiramente, conjuga as funções sintáticas e semânticas. A oposição entre coordenação e subordinação é regida pela ideia de dependência/independência, mas nem sempre há clareza quanto ao critério utilizado. As conjunções são agrupadas em dois compartimentos - o dos conectores e o dos transpositores; sendo atribuídos a eles valores semânticos. Assim, as categorias aditivas, alternativas, adversativas, explicativas e conclusivas se aplicam às coordenadas, e as causais, condicionais, concessivas, consecutivas, comparativas, conformativas, temporais, proporcionais e finais se aplicam às subordinadas. Esse tipo de abordagem leva, muitas vezes, a se considerar uma estrutura como sendo coordenadaou subordinada guiando-se pelo tipo de conector que introduz uma das partes constitutivas do período.

Por outro lado, em se tratando do sentido, Neves (1999/2006), Azeredo (2000), Mira Mateus et al. (2003), Ilari (2008) e Castilho (2010) são alguns dos autores que chamam a atenção para a dificuldade de determinar uma classificação fixa para as conjunções, pois, no uso efetivo da língua, é difícil estabelecer limites quanto aos matizes semânticos. $\mathrm{Ou}$ seja, vários sentidos podem ser acionados a partir de uma só conjunção, de forma que uma interpretação não impede a existência de outra. E sob o aspecto formal, um mesmo conteúdo pode ser expresso por meio de mecanismos relacionais distintos.

Cabe aqui uma referência a Decat (2001), que, após uma análise exaustiva do processo de combinação de cláusulas, chega a algumas conclusões, dentre as quais destacamos: i) no estudo da hipotaxe adverbial, a depreensão do tipo de proposição relacional que emerge das cláusulas é mais 
importante que a marca lexical responsável pelo elo oracional, mesmo porque outros recursos ${ }^{6}$, como a pausa, os tempos verbais, o léxico, por exemplo, podem denunciar um tipo de relação; e ii) dado que é o tipo de relação o que importa, a especificação do tipo de articulação - se coordenação ou subordinação se tornamenos relevante.

Ilari (2008) comunga desse raciocínio, como comprova a asserção:

são inúmeros os ambientes em que o falante pode escolher livremente entre coordenar e subordinar: as diferenças de sentido entre as duas escolhas parecem então imponderáveis: por exemplo, poderíamos perguntar-nos o que muda, semanticamente falando, se os exemplos encontrados no corpus fossem alterados num ou noutro sentido. [...] Se as observações acima puderem ser generalizadas a toda a classe das conjunções, dever-se-á concluir que a distinção entre coordenação e subordinação - principal critério de classificação dessas palavras em nossa tradição gramatical - não tem um correlato semântico óbvio. (ILARI, op. cit., p. 828).

Para ilustraresse fato, comparem-se as duas informações destacadas em itálico no fragmento de texto abaixo:

Até certo tempo atrás, os escândalos vinham, causavam espanto e depois iam embora. Hoje, por mais prodigiosos que sejam, (os escândalos)já vêm e vão sem causar espanto algum. É de desapontar, realmente, pois nossas últimas realizações nessa área - no estado do Amapá, [...] - tinham tudo para provocar um momentinho, pelo menos, de interesse". (Artigo da Veja, 29/09/10)

A primeira estrutura do fragmento acima: "os escândalos vinham, causavam espanto e depois iam embora” caracteriza-se como coordenada, por apresentar três orações sintaticamente independentes (ou três membros de coordenação), estando o segundo membro relacionado semanticamente ao primeiro por um vínculo de consequência e o terceiro, por um vínculo

6 A presença do conectivo facilita a percepção dos matizes semânticos expressos pelas adverbiais, mas a sua ausência, como argumenta Decat (2001), não constitui um impedimento à recuperação das proposições relacionais, ou inferenciais, pois o tempo e o modo verbais bem como a posição das cláusulas são mecanismos gramaticais que ajudam na identificação dessas proposições. 
de adição ou ordenação. Já a segunda estrutura: “(os escândalos) já vêm e vão sem causar espanto algum” revela dois mecanismos de articulação - coordenação aditiva e subordinação adverbial. Com relação à segunda estrutura, de caráter adverbial - estrutura em foco neste artigo-, interessanos destacar que ela expressa o valor de consequência (ou negação de consequência), da mesma forma que a estrutura coordenada apresentada no início do texto; porém, se modificada, resultando em: "(os escândalos) já vêm e vão, mas não causam espanto algum”, expressaria o mesmo sentido, embora a marca gramatical responsável pelo elo entre as orações seja tradicionalmente identificadora de estrutura coordenada adversativa. Logo, o falante/escritor tem à sua disposição diferentes mecanismos de organização ${ }^{7}$, no período supracitado, a opção foi pelo período misto, uma coordenada com conectivo e uma subordinada reduzida de infinitivo.

Ressaltamos aqui a probabilidade de inconsistência que ronda uma análise restrita ao nível sentencial orientada unicamente pelo tipo de conector; por outro lado, uma análise no nível do texto-discurso deverá ir além, explorando a ordem de disposição das palavras nas sentenças, a seleção lexical, entre outros aspectos. Significa dizer, aplicando essa informação ao exemplo em estudo, que, independentemente da presença dos conectivos, o uso das expressões "Até certo tempo atrás" e "Hoje" torna perceptível a mudança quanto à forma de encarar os escândalos (ou seja, há uma comparação contrastiva entre dois momentos - antes/agora). Interessa-nos observar que o modo como o autor dispõe as palavras - trata-se das mesmas palavras, sequenciadas em outra ordem -, desperta a percepção do contraste, ainda que o efeito que se pretende seja mostrar que esse estado diferente é encarado com indiferença, destituído de importância, o que termina sendo, como afirma o autor, desapontador. Percebemos, então, o quão engenhosoé o modo como o autor lida com os recursos linguísticos para conduzir a interpretação.

No início deste artigo nos comprometemos a apresentar uma atividade que permitisse explorar os mecanismos de articulação oracional contemplando diferentes níveis de análise - o sintático, o semântico e o discursivo, de modo que também tornasse possível conciliar, no processo de ensino e aprendizagem as competências metalinguística e epilinguística.

7 Nos dados analisados por Decat (2001), por exemplo, a oração subordinada, ou satélite, ora foi representada por uma única cláusula, ora por várias, processo denominado de "lista", fato que, conforme Decat (op. cit., p. 119), está condicionado aos objetivos comunicativos do falante/escritor. 
: Antes de apresentá-la, devemos um esclarecimento quanto à escolha dos : fragmentos textuais utilizados. Trata-se de fragmentos de uma entrevista, agrupados em forma de pares, tendo sido selecionados propositadamente os trechos que correspondem ao mesmo conteúdo, mas que se materializam sob formas distintas - um dos pares compreende as chamadas que vêm em negrito nesse gênero de texto, exceto no fragmento (3). Na sequência, expomos a atividade, já com a sugestão de respostas esperadas para os trechos problematizados, para não utilizar outro espaço destinado a esse fim:

\section{ATIVIDADE}

Nos três fragmentos de texto abaixo transcritos, o conteúdo informacional representado em (A) e (B), na coluna I é o mesmo; porém, as estruturas oracionais sublinhadas evidenciam modos diferentes de dizer, apresentando, pois, diferentes modos de articulação dos períodos. Compare as estruturas e, em seguida, responda o que se pede:

a) Apresente outras versões, na coluna II, utilizando o mecanismo que considerar adequado para fazer a conexão entre as orações. Feito isso,

b) especifique qual o mecanismo de combinação oracional utilizado pelo autor do texto e, depois, o que você usou. 
Fragmento (1)

\begin{tabular}{|c|c|c|}
\hline \multicolumn{2}{|r|}{ TEXTOS BASE } & NOVA VERSÃO \\
\hline A) & $\begin{array}{l}\text { A janela de oportunidades que } \\
\text { se abriu no Brasil na década } \\
\text { de } 70 \text { vai se fechar por volta } \\
\text { dos anos de } 2030 \text {. Na próxima } \\
\text { década, a população em idade } \\
\text { ativa crescerá menos do que a } \\
\text { que não está apta ao mercado } \\
\text { de trabalho. Na seguinte, de- } \\
\text { clinará em números absolutos, } \\
\text { e aí a janela demográfica se } \\
\text { fecha. É preocupante. A queda } \\
\text { da mão de obra em quadro de } \\
\text { estagnação da produtividade } \\
\text { significa o fim do desenvolvi- } \\
\text { mento. }\end{array}$ & $\begin{array}{l}\text { Na seguinte, declinará em números } \\
\text { absolutos, fechando a janela demográfica. } \\
\text { Na seguinte, declinará em números } \\
\text { absolutos, e, por isso, a janela demográfica } \\
\text { se fecha. } \\
\text { Na seguinte, declinará em números } \\
\text { absolutos, de modo que a janela } \\
\text { demográfica se fecha. } \\
\text { Na seguinte, declinará em números } \\
\text { bsolutos, o que resulta no fechamento da } \\
\text { janela demográfica. }\end{array}$ \\
\hline B) & $\begin{array}{l}\text { "Na próxima década, a popu- } \\
\text { lação ativa vai crescer menos } \\
\text { do que a que não está apta ao } \\
\text { mercado de trabalho. E queda } \\
\text { de mão de obra junto com } \\
\text { estagnação da produtividade } \\
\underline{\text { significa o fim do desenvolvi- }} \\
\text { mento". }\end{array}$ & $\begin{array}{l}\text { Portanto, queda de mão de obra junto com } \\
\text { estagnação da produtividade significa o fim } \\
\text { do desenvolvimento. }\end{array}$ \\
\hline
\end{tabular}


Fragmento (2)

\begin{tabular}{|c|c|c|}
\hline & TEXTOS BASE & NOVA VERSÃO \\
\hline & $\begin{array}{l}\text { A chave é investir na quali- } \\
\text { dade da educação? Esse é cer- } \\
\text { tamente um dos ingredientes } \\
\text { inadiáveis no Brasil. O bônus } \\
\text { retira parte da pressão por } \\
\text { quantidade, já que o número } \\
\text { de alunos cai, e abre-se espaço } \\
\text { para mirar na qualidade. Mas } \\
\text { há outros aspectos em comum } \\
\text { entre os países que souberam } \\
\text { se beneficiar do bônus demo- } \\
\text { gráfico. Eles agiram de forma } \\
\text { planejada, antecipando o fenô- } \\
\text { meno, e apostaram as fichas } \\
\text { em mais de uma frente para } \\
\text { avançar na produtividade. } \\
\text { Uma foi o desenvolvimento } \\
\text { de tecnologias, que permitem } \\
\text { tirar mais do trabalho huma- } \\
\text { no e agregar valor aos produ- } \\
\text { tos; a outra foi o investimento } \\
\text { em infraestrutura, crucial para } \\
\text { sustentar qualquer processo } \\
\text { de crescimento. O Brasil não } \\
\text { está indo nessa direção. Vive- } \\
\text { mos uma desindustrialização } \\
\text { precoce. }\end{array}$ & $\begin{array}{l}\text { O bônus retira parte da pressão por } \\
\text { quantidade, porque o número de alunos } \\
\text { cai, logo, abre-se espaço para mirar na } \\
\text { qualidade. Há outros aspectos em comum } \\
\text { entre os países que souberam se beneficiar } \\
\text { do bônus demográfico, porém. }\end{array}$ \\
\hline B) & $\begin{array}{l}\text { "Os países que souberam se } \\
\text { beneficiar do bônus demográ- } \\
\text { fico agiram de forma planeja- } \\
\text { da, apostando suas fichas em } \\
\text { mais de uma frente. O Brasil } \\
\text { não está indo nessa direção. } \\
\text { Aqui vivemos uma desindus- } \\
\text { trialização precoce". }\end{array}$ & $\begin{array}{l}\text { Os países que souberam se beneficiar do } \\
\text { bônus demográfico, como agiram de forma } \\
\text { planejada, apostaram suas fichas em mais de } \\
\text { uma frente. } \\
\text { [...] por agirem de forma planejada, } \\
\text { apostaram suas fichas em mais de uma } \\
\text { frente. }\end{array}$ \\
\hline
\end{tabular}


Fragmento (3)

\begin{tabular}{|c|c|c|}
\hline \multicolumn{2}{|r|}{ TEXTOS BASE } & NOVA VERSÃO \\
\hline A) & $\begin{array}{l}\text { E quais são as consequências } \\
\text { disso? Como não fez seu de- } \\
\text { ver de casa para ingressar na } \\
\text { competição com o mundo, o } \\
\text { país continuou dependendo } \\
\text { do agronegócio, que gera re- } \\
\text { cursos, sim, mas não fecha a } \\
\underline{\text { conta. }}\end{array}$ & $\begin{array}{l}\text { O país não fez seu dever de casa para } \\
\text { ingressar na competição com o mundo; } \\
\text { em vista disso, continuou dependendo do } \\
\text { agronegócio, que, embora gere recursos, não } \\
\text { fecha a conta. }\end{array}$ \\
\hline B) & $\begin{array}{l}\text { O emprego em baixa afeta } \\
\text { algum grupo mais do que os } \\
\text { outros? Afeta sobretudo as } \\
\text { mulheres. [...] Entre } 1950 \text { e } \\
\text { 2010, a presença masculina } \\
\text { cresceu três vezes, ao passo que } \\
\text { a feminina subiu dezesseis. } \\
\text { Elas foram a grande novidade } \\
\text { demográfica no grupo dos } \\
\text { trabalhadores. Mas o número } \\
\text { de mulheres estancou à medi- } \\
\underline{\text { da que a qualidade dos postos }} \\
\text { caiu. [...] }\end{array}$ & $\begin{array}{l}\text { Entre } 1950 \text { e 2010, a presença masculina } \\
\text { cresceu três vezes, enquanto a feminina } \\
\text { subiu dezesseis. } \\
\text { Se, por um lado, elas foram a grande } \\
\text { novidade demográfica no grupo dos } \\
\text { trabalhadores, por outro lado, o número } \\
\text { de mulheres estancou à medida que a } \\
\text { qualidade dos postos caiu. [...] }\end{array}$ \\
\hline
\end{tabular}

Se a metalinguagem já foi tema de discussão, dividindo opiniões em relação ao fato de dever ou não ser objeto de ensino, atualmente, esse aspecto já não é tão polêmico, pois, ainda que a prioridade seja dar condições para que os usuários da língua saibam utilizar os diferentes registros, adequando-os às diferentes situações comunicativas, implicando também reconhecer e se apropriar das sequências linguísticas peculiares aos variados gêneros de texto, tudo isso requer o conhecimento gramatical e esse vai demandar o uso de rótulos metalinguísticos. O ponto de partida para a compreensão da gramática pode não ser a metalinguagem, mas, após refletir sobre os usos, nada impede que se trabalhe a nomenclatura, pois se trata de princípios de organização que permitem a compreensão do sistema linguístico, auxiliando na descrição/análiseda organização sintática da língua, das relações semânticas estabelecidas entre os elementos linguísticos e das motivações externas que influenciam os usos. 
Exercitar maneiras distintas de dizer a mesma coisa, analisar as diversas sutilezas que alterações de sequência ou inversão e de escolha léxico-gramatical imprimem à produção de um texto, certamente, pode se constituir em importante estratégia para promover a reflexão sobre a configuração sintática da língua. Talvez, assim, epilinguisticamente, seja possível conduzir o aluno pelo caminho de valorização da forma linguística e sua metalinguagem, instruindo-o a perceber que esta estará sempre a serviço de uma função, seja textual, discursiva, ou simplesmente comunicativa.

Diversos estudos de base funcionalista criticam o tipo abordagem feito pela tradição. Decat (2001) ilustra várias situações em que um só conectivo permite mais de uma inferência, evidenciando ambiguidade de sentido. Segundo a autora (op.cit., p. 123), esse fenômeno possivelmente é consequência do "esvaziamento semântico de algumas expressões conjuntivas, que é comum na língua oral e já vem sendo exibido na língua escrita”. Sendo assim, "a decisão sobre qual das duas inferências é a predominante só será possível no nível do discurso.” Castilho (2010, p. 373) afirma serem as adverbiais menos estruturadas sintaticamente, porém, mais sensíveis às necessidades do discurso. Essa relevância do discursofoi destacada quando nos referimos a Halliday (1985), para quem a articulação entre uma oração matriz e uma adverbial, também denominada de cláusula de realce, resulta de escolhas discursivas, além de Matthiessen e Thompson (1988), que concebem as relações entre uma oração matriz e uma subordinada adverbial, ou satlite, como similares às relações estabelecidas quando da organização do discurso.

O propósito da atividade ilustrada foi exatamente explorar os variados modos de articulação oracional, procurando mostrar que uma mesma informação pode ser codificada por meio de uma estrutura coordenada ou subordinada, devendo ficar claro que uma estrutura pode ser mais complexa que outra, exigindo mais a atenção para outros aspectos estruturais, como a pontuação, a concordância, a ordem, etc. Em relação ao uso dos conectores, também é preciso observar a adequação ao contexto, servindo de pistas para a sua utilização os vocábulos que estão no entorno. 


\section{CONSIDERAÇÕES FINAIS}

Neste artigo, procuramos enfatizar a existência de uma relação : entre sintaxe e organização textual e discursiva, destacando a influência do contexto nas escolhas linguísticas, ou seja, na forma de organização dos enunciados. Alertamos para a insuficiência do estudo das orações adverbiais restrito à identificação dos valores semânticos inerentes aos conectores que introduzem tais orações, dado que, do ponto de vista semântico, a depreensão das relações estabelecidas entre as porções textuais dependeria da inferência de informações e não somente da identificação de uma tipologia oracional fixa.

Desse modo, expomos a relevância de propor atividades escolares que suscitem reflexões sobre as escolhas que os usuários realizam, considerando-se que têm a sua disposição um leque de alternativas e de recursos de articulação das informações em relações paratáticas, hipotáticas ou de subordinação reveladoras dos mais diversos matizes semânticos e discursivos.

Além disso, alertamos para o fato de que restringir a análise às determinações da gramática tradicional, essencialmente dicotômica quando se trata de articulação oracional, representa uma opção por ignorar as sutilezas contidas nas estratégias argumentativas ativadas pelos usuários da língua nos variados contextos comunicativos. Não nos esqueçamos de que esses recursos são reveladores de intenções e propósitos os mais diversos, só atestados quando se analisa dados de língua em uso, desvinculando-se o analista - de amarras metodológicas acorrentadasà tradição.

\section{REFERÊNCIAS BIBLIOGRÁFICAS}

ANTONIO, Juliano Desiderato. Estrutura retórica e combinação de orações em narrativas orais e escritas do português brasileiro. In: Estudos linguísticos. São Paulo, 37 (1) 223-232. Jan-abr. 2008.

AZEREDO, José Carlos de. Fundamentos de gramática do português. Rio de Janeiro: Jorge Zahar, 2000.

AZEVEDO, João Luiz Ferreira de. Consequências discursivas e semânticas da mobilidade das orações finais no português escrito. Revista Univ. Rural. Sér. Ciências Humanas. Vol. 24 (1-2): 11-34, jan./jun., 2002. 
BECHARA, Evanildo. Moderna gramática portuguesa. 38. ed. Rio de Janeiro:

: Lucerna, 1999/2003.

CASTILHO, Ataliba T. de.Nova gramática do português brasileiro. São Paulo: Contexto, 2010.

CASTILHO, Ataliba T. de; ILARI, Rodolfo; NEVES, Maria Helena; BASSO, Renato M. O advérbio. In ILARI, Rodolfo; NEVES, M. H. M. (orgs.). Gramática do português culto falado no Brasil. VOL. 2, Campinas: Unicamp, 2008.

CUNHA, Celso e CINTRA, Luís F. L. Nova gramática do português contemporâneo. Rio de Janeiro: Nova Fronteira, 2001.

DECAT, Maria Beatriz Nascimento (et al.). Aspectos da gramática do português: uma abordagem funcionalista. Campinas: Mercado de Letras, 2001.

DIK, Simon. Functional grammar. Dordrecht-Holland/Cinnaminson: Foris Publications, 1978.

. Studies in functional grammar. London: Academic Press, 1980.

DUARTE, Inês. Aspectos lingüísticos da organização textual. In: MIRA MATEUS, Maria $H$. et alii..Gramática da lingua portuguesa. Coimbra, Almedina, 2003.

HALLIDAY, Michael A. K. Anintroduction do functionalgrammar. 2 ed. London: Edwards Arnold Publishers Ltd., 1985.

HOPPER, Paul.; TRAUGOTT, Elizabeth C. Grammaticalization. Cambridge: Cambridge University Press, 1993.

ILARI, Rodolfo. As conjunções. In: ILARI, Rodolfo; NEVES, Maria Helena Moura (orgs.). Gramática do português culto falado no Brasil. VOL. 2, Campinas: Unicamp, 2008, p. 809-860.

ILARI, Rofolfo; CASTILHO, Ataliba Teixeira de; ALMEIDA, Maria Lúcia Leitão de; KLEPPA, Lou-Ann; BASSO, Renato Miguel. A preposição. In: ILARI, Rodolfo; NEVES, Maria Helena Moura (orgs.). Gramática do português culto falado no Brasil. VOL. 2, Campinas: Unicamp, 2008, p. 623-804. 
ILARI, Rodolfo; NEVES, Maria Helena Moura (orgs.). Gramática do português culto falado no Brasil. VOL. 2, Campinas: Unicamp, 2008.

LEHMANN, Christian. Towards a typology of clause linkage. In: HAIMAN, john e THOMPSON, Sandra. A. Clause combining in grammar and discourse. Amsterdam/Philadelphia: John Benjamins Publishing, 1988.

MANN, William C. \& THOMPSON, Sandra A.Relational propositions in discourse.Califórnia, Califórnia: University of SouthenCalifórnia, 1983.

; THOMPSON, Sandra A. Rhetorical Structure Theory: toward a functional theory of text organization. Text 8(3): 243-281, 1988.

MIRA MATEUS, Maria Helena et alii.Gramática da língua portuguesa.5. ed. revista e aumentada. Lisboa: Caminho, 2003/2005.

MATOS, Gabriela. Estruturas de coordenação. In: MIRA MATEUS, Maria H. et alii. Gramática da língua portuguesa.5. ed. revista e aumentada. Lisboa: Caminho, 2003.

MATTHIESSN, Christian and THOMPSON, Sandra The structure of discourse and "subordination". In: HAIMAN, J.; THOMPSON, S. (Ed.) Clause combining in grammar and discourse. Amsterdam: John Benjamins Plublishing, 1988. p. 275-392.

NEVES, Maria Helena Moura. Gramática de usos do português. São Paulo: Editora Unesp, 2000.

. Texto e gramática. São Paulo: Contexto, 2006.

- A gramática passada a limpo: conceitos, análises e parâmetros. São Paulo: Parábola Editorial, 2012.

NEVES, et al. As construções hipotáticas. In: In: ILARI, Rodolfo; NEVES, Maria Helena Moura (orgs.). Gramática do português culto falado no Brasil. VOL. 2, Campinas: Unicamp, 2008, p. 937-1014.

PERINI, Mário. Gramática descritiva do português. São Paulo: Ática, 1996. 